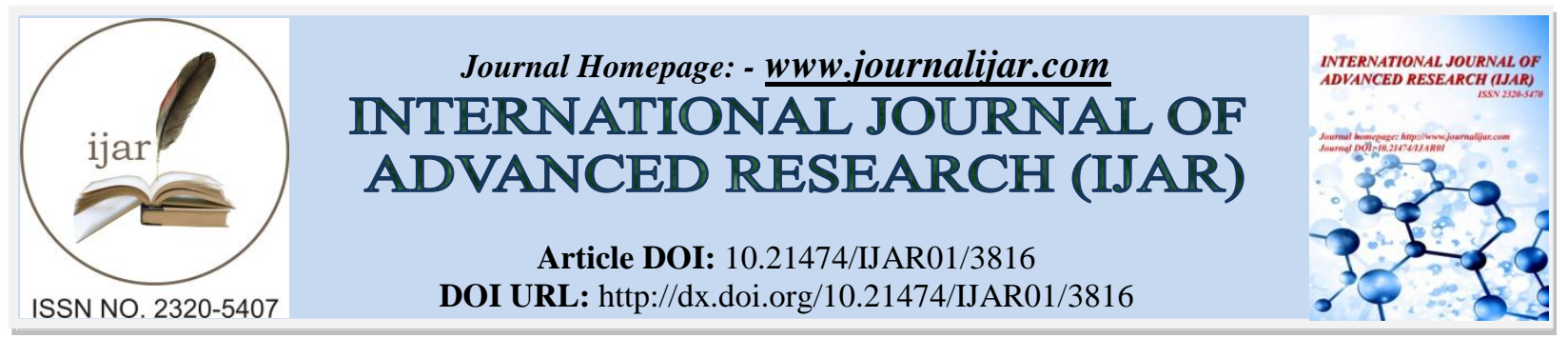

RESEARCH ARTICLE

\title{
ASSESSMENT OF WASTEWATER TREATMENT IN DEVELOPING COUNTRIES CURRENT PRACTICES IN VIENTIANE CAPITAL, LAOS.
}

\section{"Minaphone Chanthavilay, Hongtao Wang, Wang Ying and Fengting Li.}

1. UNEP-IESD, TONGJI Institute of Environment for Sustainable Development, College of Environmental Science and Engineering, Tongji University, Siping Road 1239, Shanghai 200092, P.R.China.

2. Department of Public Works and Transport, Vientiane Capital, Lao P.D.R.

\section{Manuscript Info}

\section{Manuscript History}

Received: 02 February 2017

Final Accepted: 06 March 2017

Published: April 2017

\section{Key words:-}

wastewater, Vientiane, Decentralized, wastewater, Water, Canals

\begin{abstract}
With rapid urbanization many people are attracted to the cities. Some of them settle on the banks of canals and water bodies. These settlements which often have inadequate infrastructure become source of pollution of water bodies. This study also showed the main problem of waste water in Laos and current situation of waste water management in Laos, focus on decentralized wastewater treatment systems and public canals of Vientiane capital city. Decentralized treatment can improve access to wastewater infrastructure in developing regions and improve energy efficiency in reclamation in many rapidly growing developed regions. The result of the study suggest that the government should early Implementation of the Structural Water Environment Improvement Plan, Prevention of Concrete Covering on Drainage Systems and Conservation of Marshes/Wetlands
\end{abstract}

Copy Right, IJAR, 2017,. All rights reserved.

\section{Introduction:-}

Urbanization is generally a beneficial process in many cities of developing countries. However, beside the beneficial it also generates many problems to city authorities. The wastewater generated by many activities in urban areas, the main pollution environmental problems that authorities dealing with wastewater pollution. Wastewater can be a source of waterborne diseases if wastewaters are discharged to water bodies and other place within being treated. Untreated water or wastewater has also been classified as the major source of pollutants resulting in contamination of aquatic plants and animals [1]. Though, many city authorities are trying to implement wastewater treatment while trying to reduce waste water generation. The successes are limited due to many factors. Like in any other countries with scare water resources, Laos is also concerned with its growing incidence of water pollution brought about by inappropriate wastewater discharge practices.

Vientiane Capital, which is the capital city of Lao PDR, it is located on an alluvial plain along the left bank of Mekong River east to west. The area of capital is about $3.920 \mathrm{~km}^{2}$ and the elevation of the ground ranges from $160 \mathrm{~m}$ to $170 \mathrm{~m}$ above the sea level. The city comprises nine districts; the population is around 820.900 people [2]. There are designed for urbanization extends along the left bank of Mekong River and occupies an area of $210 \mathrm{~km}^{2}[3]$. As now a day the situations of water quality in natural resources is become to special issue in many countries in the world. Such as sewerage in the Vientiane Capital is at present being considered as a serious problem especially in urban area, where major development and growth are expected. Such future development without effective sewerage

Corresponding Author:- Minaphone Chanthavilay.

Address:- UNEP-IESD, TONGJI Institute of Environment for Sustainable Development, College of 
system in place in the city will result in more pollution to the natural water resources. Since there are no separate wastewater pipe network, untreated wastewater from all areas are disposed to the nearby drainage system, as result quite dark color water with a lot of garbage on the surface of water especially in the dry season can be observed in most of the open channels or canals in the urban area. This is very clear indication of deteriorating water environment in the city.

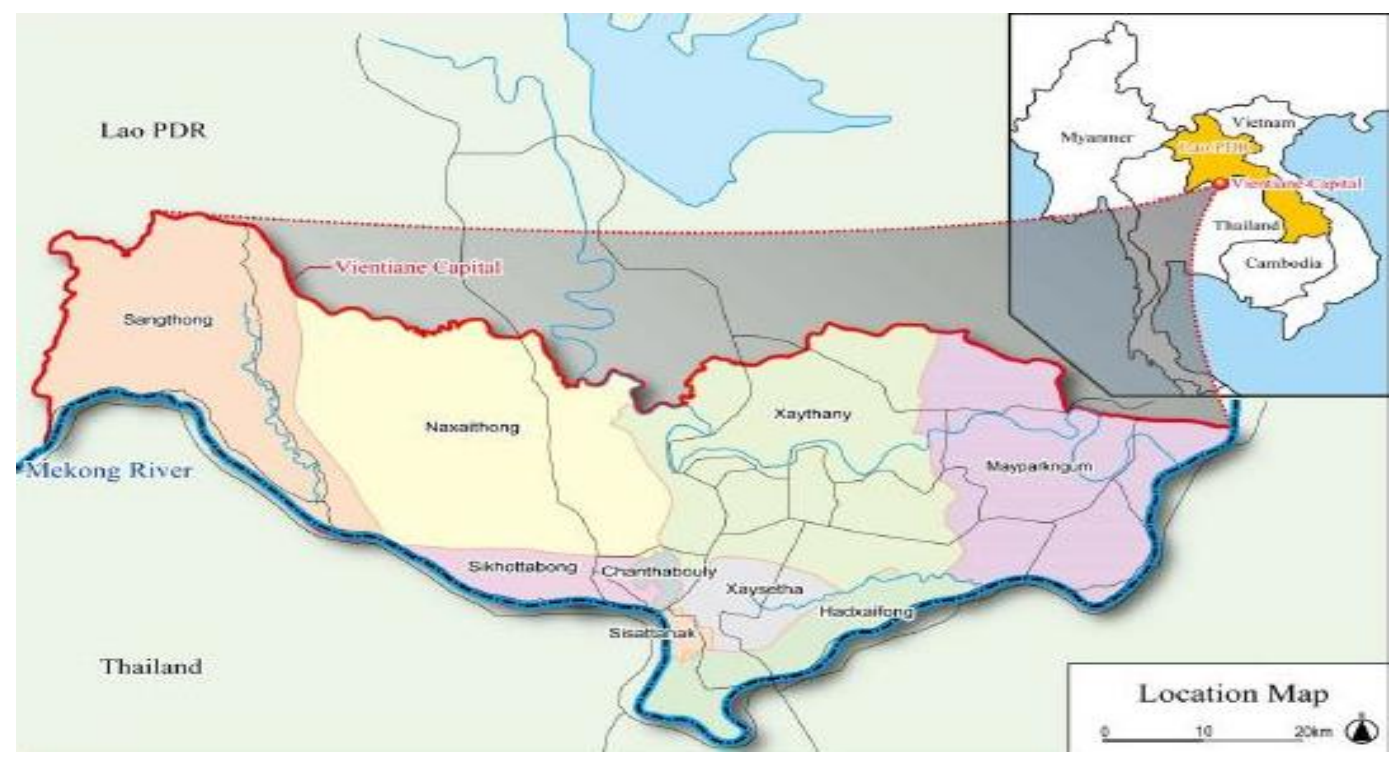

Figure 1:- Map of Vientiane Capital City in Laos.

\section{Wastewater Situation in Vientiane Capital:-}

Wastewater treatment as part of the sanitation system is an important environmental service that is closely linked to water management. The poor sanitation management in Lao PDR generally contributes to wastewater pollution especially in the urban areas. The major water source for urban supply is surface water since most towns are located along the rivers as groundwater is for the rural population. In Vientiane capital city, current wastewater handling in most urban areas entails on-site disposal system of human waste and black water, either without treatment or with poorly functioning treatment. The increase of pollution and steady decline in drainage water quality is becoming a serious challenge in the management of Vientiane's water resources as it becomes more and more urbanized[4]

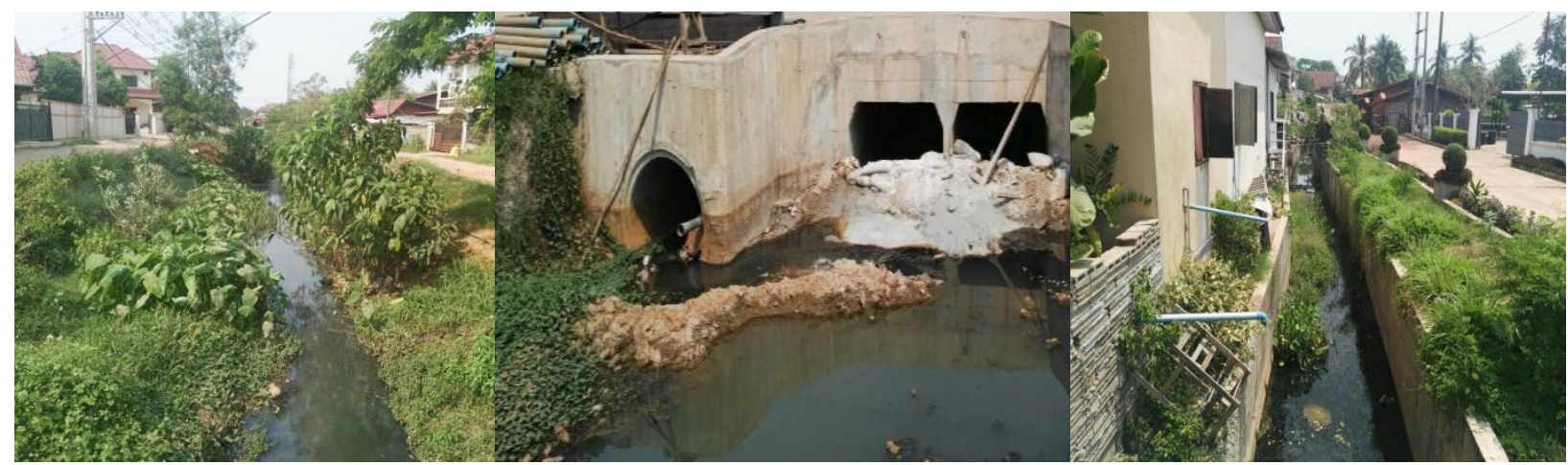

Figure 2:- Water quality in the canals has been getting worse. 


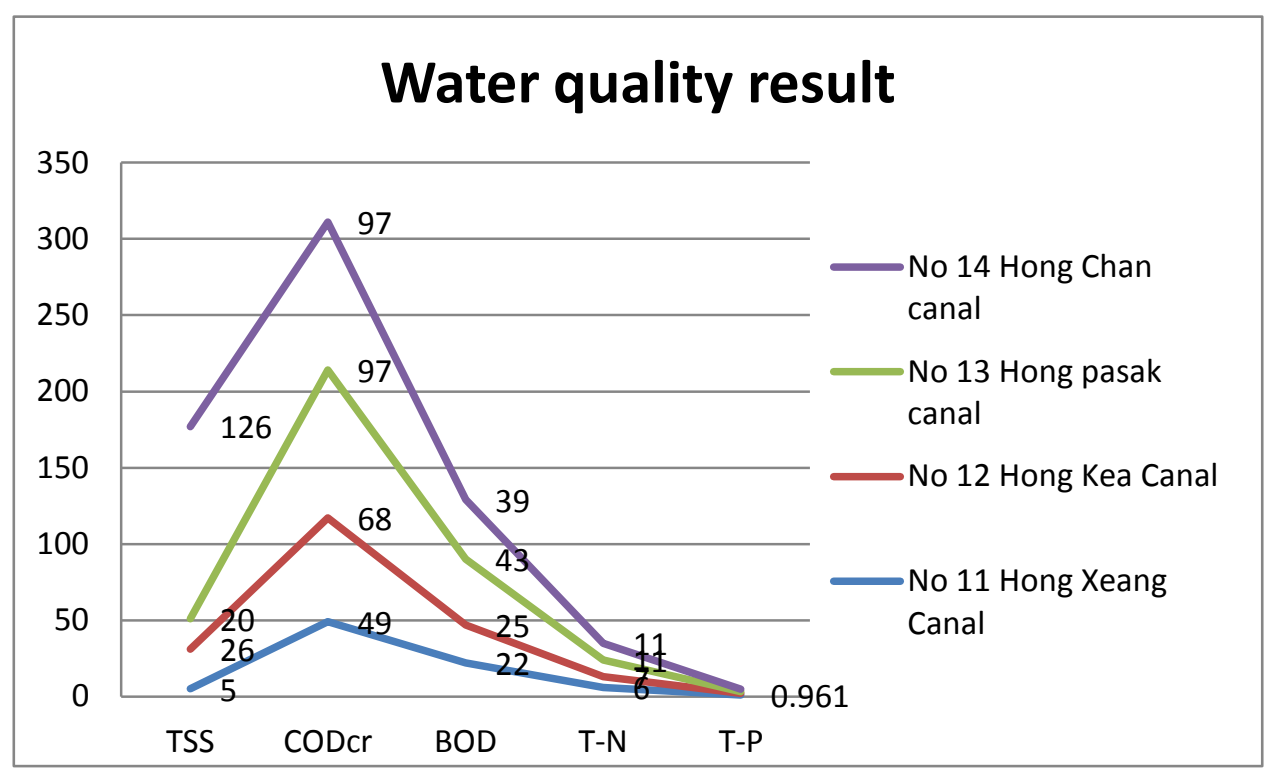

Besides that, Surface water along the urban drainage canals has been deteriorating due mainly to domesticorganic pollutants mostly generated from the daily activities of residents as well as commercial activities. Based on the simulation results, this condition would much worsen in future. Among the urban drainage canals, Hong Chan and Hong Pasak, which receive wastewater discharged from the urban center of Vientiane, have the most seriously deteriorated water quality with BOD concentrations of 30 to $40 \mathrm{mg} / \mathrm{l}$ at present. In future, more serious BOD concentrations exceeding $40 \mathrm{mg} / \mathrm{l}$ are projected in the entire stretch of the urban drainage system including Hong Ke and Hong Xeng.[5]

The growing number of industries has increased the incidence and risk of pollution. The larger mills and industries of concern in Lao PDR are pulp and paper, timber, food processing, garment manufacturing and cement factories and gravel pits [6]. Most of these have only limited wastewater treatment systems for reducing waste concentration sand loads in the final effluent discharge to waterways. A study on wastewater management and building in Vientiane (2004) reported that, with a rapidly growing population in the urban area of Vientiane Capital City, sewerage is becoming a serious problem because of the lack of a sufficient drainage system and lack of sewerage systems, while on-site sewerage disposal or septic tanks are often poorly designed. Further contributing to the problem in urban area is stagnant untreated wastewater from households and some small industries with open roadside drains, flowing directly into marsh or natural channels. This mixing of sewerage in the storm drainage system will continue to have a detrimental impact on public health [7].These are all the significant potential problems that would arise from water pollution among urbanization.

\section{Current wastewater situation in Vientiane city:-}

Wastewater Generation:-

Approximately $85,000 \mathrm{~m} 3$ of wastewater from the urban area is drained to the public waterways every day, only about half of which is treated by the current on-site treatment system such as septic tanks and contributes in reducing the pollution.[8]. Due to natural purification and dilution from existing water channels, ponds and rivers and the limited wastewater load from the current population, the water quality in the natural waterway is still not so severe, only some points during dry season in the water channel can be noticed with dark color.

\section{Sanitation Facility:-}

According to the National Statistics in 2005, approximately 90\% of households in Vientiane Capital have an access to proper toilet facilities. This shows that sanitary coverage is relatively good, but methods adopted in general for treatment is not satisfactory and maintenance is poor [9]

\section{Collection and Treatment:-}

Currently, there is no separate wastewater collection system in Vientiane City or in other provinces of Lao PDR. Only some sewerage pilot projects had been constructed on a small scale basis by the EU/DANIDA in year 
1994/2004. The service area is a center of urban Vientiane city around the Nong Chan marsh and the Northwestern part of the That Luang Marsh, where pilot stabilization pond $(140 \mathrm{~m} \mathrm{x} 410 \mathrm{~m})$ suitable to treat wastewater in hot climatic condition by utilizing the natural biological treatment with less maintenance was developed. But due to a failure of the pumping stations in 2008, the plant has stopped its operation and the facilities have been devastated. Natural marsh or ponds are mostly used as a natural wetland treatment system. Especially, the That Luang Marsh, which is a very large marsh next to the urban area has been mentioned as good wetland and flood retention pond by several studies [10]

\section{Drainage System:-}

Urban area of Vientiane Capital is covered by 2 main catchments areas (a) Hong Xeng system consists of Hong Xeng and its tributaries, Hong Kai Keo, (b) Hong Kesystem consists of Hong Ke and its tributaries. These areas are a sub-catchment area of the Mak-Hiao River[11]

\section{Wastewater Treatment facilities:-}

Vientiane has no public wastewater treatment system and sewage has long been naturally treated through the marsh in the region. Moreover, sewage of some buildings is discharged through septic tank, and even existing septic tanks are too deteriorated to That Luang marsh in the east through combined sewer pipe and channel before flowing into Mekong River. Marsh serves the lagoon but the area of marsh in urban area has been deceased and could hardly accommodate the increasing contamination and sewage. Though the large scale That Luang Marsh serves the lagoon, it would be decreased due to growing urbanization.

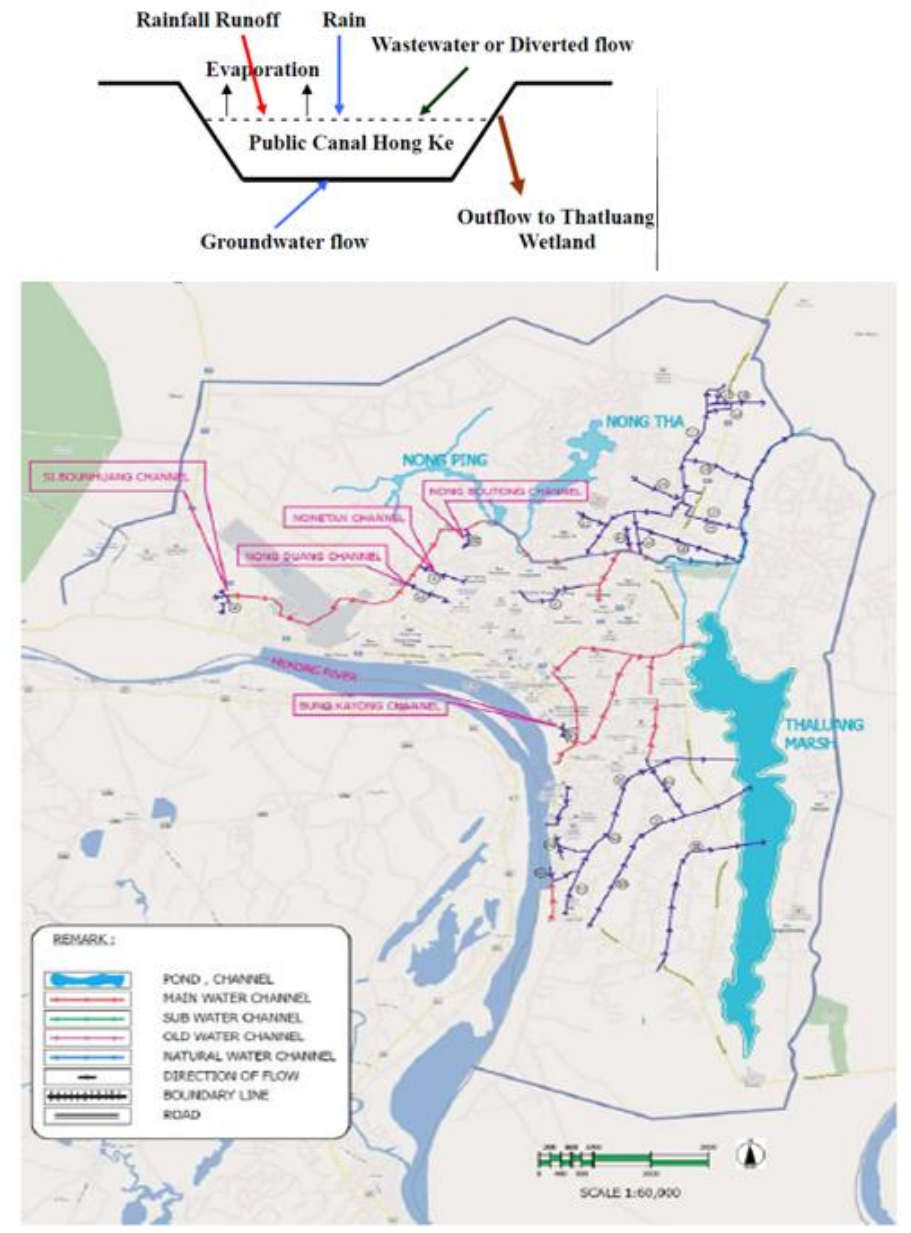

Figure 3: Existing Drainage System in Urban Vientiane Capital. 


\section{Strategy on sanitation and Waste water management in Laos:-}

Government strategy for waste water system development:

The model of waste water treatment system will be apply with appropriated districts criteria that will be onsite (Dry pit, septic tank) or outside treatment with DEWATS or Centralized system. Some districts or cities can be only DEWATS or mixed between DEWATS and Centralized system that depend on each criteria districts/cities .The solution from 2014-2030, the Urban sanitation development strategy will be focused on DEWATS system as a key method for waste water treatment system in both urban and suburban area including rural area[12]. The model of waste water treatment system will be apply with appropriated districts criteria that will be onsite (Dry pit, septic tank) or outside treatment with DEWATS or Centralized system. Some districts or cities can be only DEWATS or mixed between DEWATS and Centralized system that depend on each criteria districts/cities. The solution from 2014-2030, the Urban sanitation development strategy will be focused on DEWATS system as a key method for waste water treatment system in both urban and suburban area including rural area.[13]

\section{The Characteristic of DEWATS in Laos:-}

Decentralized Wastewater Treatment Systems (DEWATS) is a technical approach rather than merely a technology package. DEWATS applications are based on the principle of low-maintenance since the most important parts of the system work without technical energy inputs and cannot be switched off intentionally. State-of-the-art technology is being offered in DEWATS applications at affordable prices since all of the construction materials are being sourced out locally. The major benefit of decentralized wastewater systems is improvement of human health and ecosystem in any area where they are used. This is due to the elimination of illegal discharges into surface rivers and the removal of failing or poring performing soil absorption systems that contaminate the groundwater supply [14]The decentralized wastewater treatment concept will not be the answer to all wastewater management problems. There are many potential benefits of this alternative technology indicate that it is a system which deserves much larger attention, particularly in smaller communities and the developing urban fringe [15]Technologies of DEWATS.

The basic technologies of the DEWATS used in all three of these projects are basically identical, with differences only in treatment capacity. This module of DEWATS used by BORDA-LIRE consists of the following sections, in order of wastewater flow: control boxes, grease trap, primary settling unit, anaerobic baffled reactor, anaerobic filter, and discharge pipe. Control boxes are valves placed at each connection from a toilet /septic tank to the main drainage line. A grease trap is a simple tank, one or two chambers, with influent and effluent pipes positioned fairly deep below the anticipated water level. Since grease (oil) floats on water, influent grease rises to the surface and is trapped there, while the remaining wastewater exits through the sunken effluent pipe.[16]

1. Settler

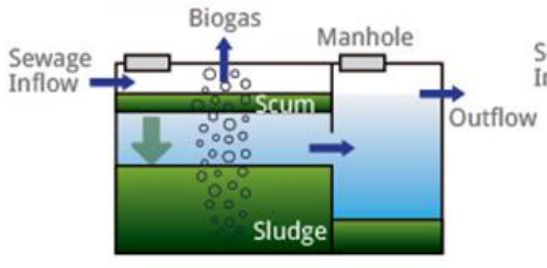

3. Anaerobic Filter

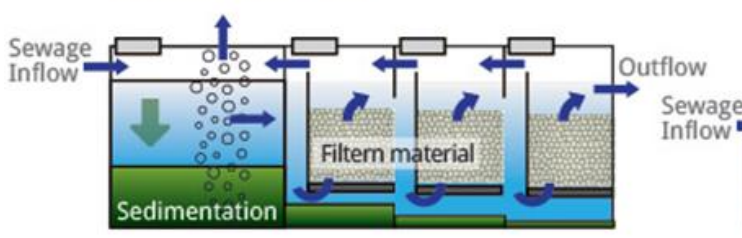

4. Planted Gravel Filter

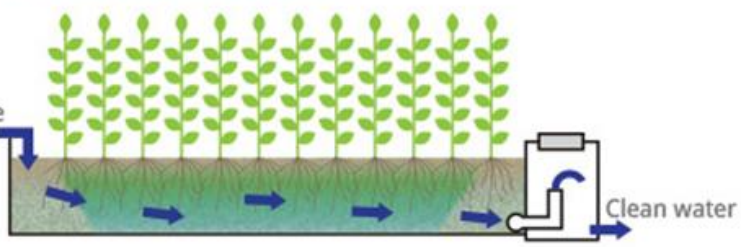

Main DEWATS modules for physical and biological wastewater treatment Case studies of Decentralized Wastewater Treatment Systems (DEWATS) in Vientiane city. 


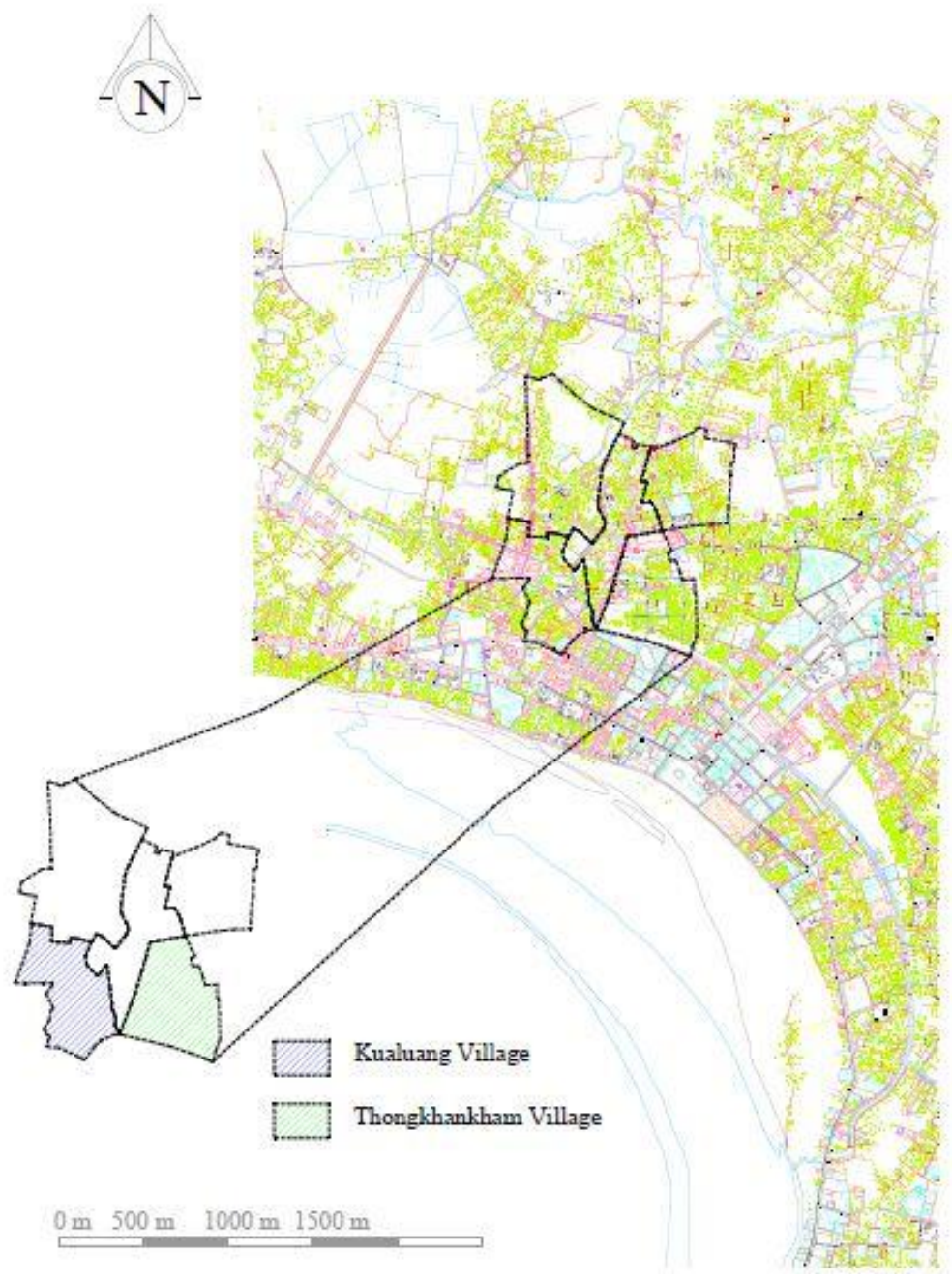

Case study of decentralized wastewater treatment in Vientiane, Kualuang Temple and Kualoung School and Thongkhankham village.

For the first project in Thongkankham Village, the DEWATS was connected to 22 households and 1 noodle-making shop, with approximately 146 total users. As well, 9 of the households also received toilet renovations, which make them the most direct beneficiaries of the project. The improvements made in wastewater management, however, extend beyond the 146 users, and other residents in the Village area will also benefit from the reduction in groundwater pollution, foul odor, and poor drainage. For the second project in Khoualuang Primary School and Temple, there are approximately 116 students and monks who are now covered by the DEWATS. As well, since the project included renovation of the school toilets, the students will now be able to enjoy this additional benefit. The residents of the surrounding area will also benefit from the reduction of foul odor, groundwater pollution, and flooding from these nearby sanitation improvements. The most direct beneficiaries of a less polluted stream, though, will be the residents living along it on its lower banks, who draw water from it for their daily use. 


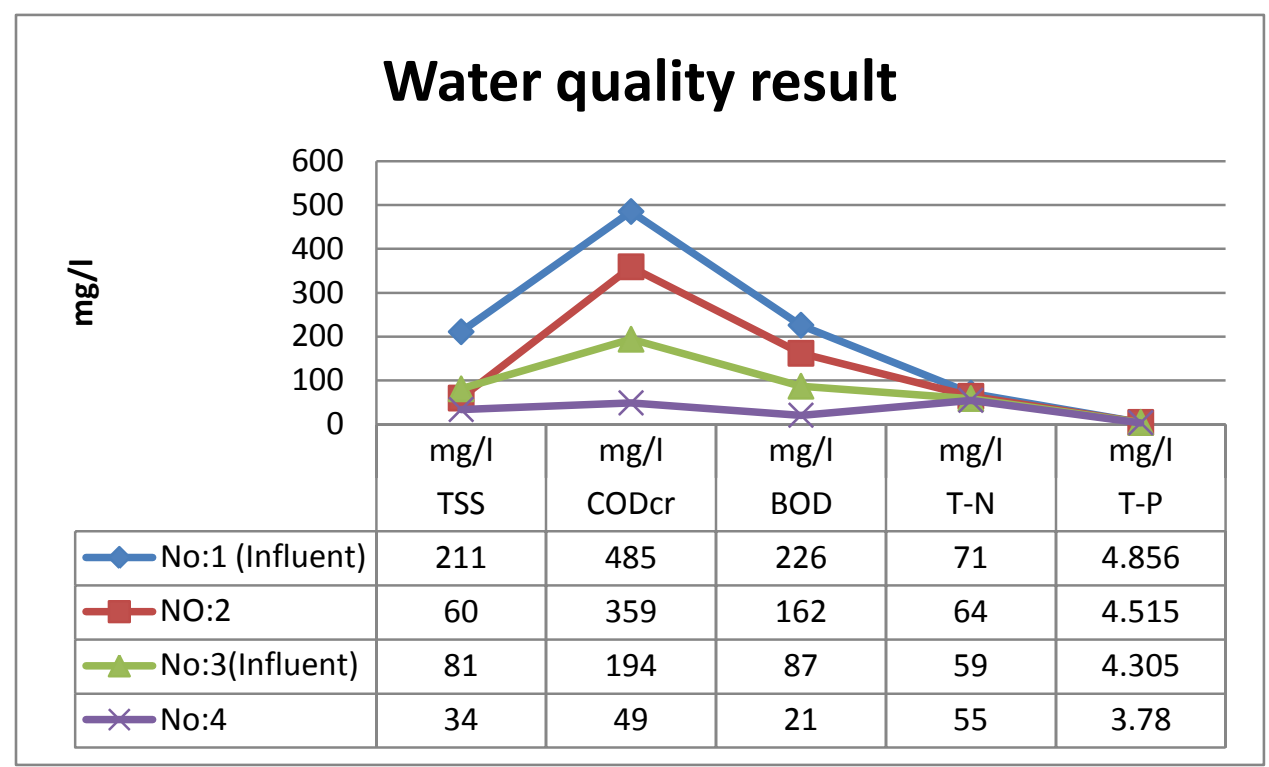

Remark: No1: Inlet- Thongkhankham (Community)

No 2: Outlet - Thongkhankham (Community)

No 3: Inlet- Khualung (School)

No 4: Outlet- Khualung (School)

The water quality testing carried out upon the completion of each project indicates the efficient nature of the DEWATS design. The three projects, Thongkankham, Khoualuang school and khoualuang temple, had influent BOD and COD values (in milligrams per liter) of 226/485, 87/194 respectively, which do not comply with any national discharging regulations. However, the resulting effluent BOD and COD (in $\mathrm{mg} / \mathrm{L}$ ) after treatment at these three projects was $162 / 21,359 / 49$, which comfortably complies with the respective national standards of 200/400, 40/130, and 60/350, respectively, for this projects. These values should continue given proper operation management and indicate that these projects were successful in their objective of treating the wastewater from these communities to reduce groundwater pollution, foul odors, and health risks[17]

\section{Conclusion and Recommendations:-}

Based on the current practices and challenges, here we propose the following recommendations for the improvement of water and wastewater treatment in Vientiane capital, Laos. Urbanization in Vientiane has been rapidly progressed, and natural environment in the urban areas has been deteriorated in parallel. The natural environment, however, still significantly remains in Vientiane in remediable level, so that it shall be urgent issues to conserve the remaining natural environment and to restore the lost one. In finalizing this paper, those points and issues are summarized to provide some help in the future improvement of water environment.

1. Early Implementation of the Structural Water Environment Improvement Plan

Rapid urbanization in Vientiane has been progressing in a very fast pace. As frequently described, water environment improvement shall consist of the integrated man-made treatment facilities and the natural purification functions of marshes, ponds and river courses as natural assets given to the Vientiane residents from the physical improvement viewpoint. In this regard, the first step of the improvement works shall be started as early as possible, so that the residents can understand the importance of conservation of their precious environment. This process could be easily linked to the enhancement of people‘s awareness on environmental improvement.

\section{Prevention of Concrete Covering on Drainage Systems}

Hong Thong receives wastewater and rainwater from the most congested areas of Vientiane,vsimilar to Hong Pasak. Hong Thong joins Hong KhouaKhao near the NongChanh Marsh, and changes its name to Hong Ke. Hong Thong has been covered with concrete slabs in almost all its stretch. Although the concrete covering is one of the alternatives to make people disregard the offensive odor and deteriorated scenery of worsened water quality, difficulties on the improvement of water environment will come out due to the invisibility of existing conditions of 
water quality and the inability of conducting improvement works as well as monitoring their effects. Conducting possible improvement measures on the water environment in a step-by-stepmanner would rather be recommended than removing the deteriorated environment from theurban residents ${ }^{6}$ vision.

\section{Conservation of Marshes/Wetlands:-}

Rapid urbanization, however, has been progressing in/around the That Luang Marsh, so that it isnecessary to conserve the marsh areas and their functions and protect them against theurbanization of Vientiane. Furthermore, the remaining marshes in the urban areas, such as NongChanh, Nong Bo, and NongTha, shall be conserved as well. Unless conservation measures are undertaken, a similar urbanization process, where various wide mashes had existed in the past have been reclaimed into urban areas, would occur in the remaining marshes mentioned above. In order to conserve these remaining marshes and wetlands, the following two conservation approaches are necessary.

\section{References:-}

1. Institute for Global Environment Straegies, (2003). Urban Environmental management Challenges in Asia. Kanagawa, Japan: IGES. p.23

2. Ministry of planning and investment, Lao statistics bureau, statistic yearbook 2015, p. 36

3. JICA (2011).'The study on improvement of water environment in Vientiane city" final report.p. 30.

4. JICA (2009). "The study on improvement of water environment in Vientiane city" Inception report.p.12

5. JICA (2010). "The study on improvement of water environment in Vientiane city" Inception report.p.22

6. Ministry of Industry and commerce, MIC (2009), regulation for noise standard from the industrial factory in 2009. P, 11

7. Gerrard, P. (2004). Integrating Wetland Ecosystem Values into Urban Planning: The Case of Thatluang Marsh, Vientiane, Lao PDR, and IUCN - the World Conservation Union Asia Regional Environmental Economics Programming WWF Lao Country Office, Vientiane, Lao PDR.

8. ADB (2001). Final Report, Sanitation, Drainage and Waste Water Management.Vientiane Urban Infrastrucer and Services Project ADB-TA 3333-LAO- Vientiane Urban Development and Administration Authority.

9. 9). Ministry of planning and investment, Lao statistics bureau, statistic yearbook 2005, p. 35

10. SETA.,(2005) Wastewater management of Thatlouang Marshes. Final report, Vientiane capital, p.19.

11. DANIDA (1998). Environmental Problems of the Energy Sector, Presentation to DANIDANatural Resource and Environment Program, DANIDA, Vientiane.

12. Atsanavong, L.(2004). Prospects for Implementing decentralized sanitation systems in Underserved communities: a case study of Thongkhankham-NueBillage in Lao PDR. Bangkok: Asian Institute of Technology

13. SFNSDS. 2008. Strategic Framework for National Sustainable Development Strategy for Lao PDR, 2008

14. Southwest Virginia Regional Wastewater study, 2005).Decentralized Managed Wastewater System (DMWS), p.22.

15. Van Lier, Pol, seeman, and Lettinga. (1998). Decentralized urban sanitation concepts: Perspectives for reduced water consumption and wastewater reclamation for reuse, EP\&RC Foundation, Wageningen (The Netherlands), Sub-Department of environment Teachonology, Agricultural University. P.18.

16. BORDA-LIRE. (2010). LIRE-BORDA constructs sanitation facility for community, school and temple in Vientiane. P.5

17. UNICEF/World Health Organization, Joint Monitoring Program for Water Supply and Sanitation, 2012. Progresson Drinking Water and Sanitation. 2012 Update. P.16. 
Supporting information.APPENDIX 1

Lao People's Democratic Republic Peace Independence Democracy Unity Prosperity

Department of Irrigation

Irrigation Science Research Center

To: Nihon Suido Consultants Co., Ltd.

Head Office

22-1, Nishi-Shinjuku 6-Chome, Shinjuku-ku, Tokyo 163-1122, Japan

Tel: +81-3-5323-6265; Fax: +81-3-5323-6487

Attention: Mr. Kazuhiro Asada

Project: The Project for Urban Water Environment Improvement in Vientiane Capital

Subject: WATER QUALITY ANALYSIS

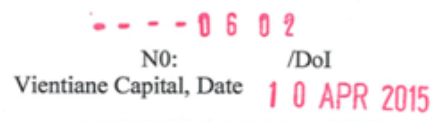

Result of Water Quality Analysis

Registration date: 01/04/2015 Sampling by : Project's staff

\begin{tabular}{|l|c|c|c|c|c|c|c|c|}
\hline \multicolumn{1}{|c|}{ Parameters } & Unit & N0: 1 & N0: 2 & N0: 3 & N0: 4 & N0: 5 & N0: 6 & N0: 7 \\
\hline TSS (Total Suspended Solid) & $\mathrm{mg} / \mathrm{l}$ & 211 & 60 & 81 & 34 & 34 & 6 & 12 \\
\hline COD (Chemical Oxygen Demand) & $\mathrm{mg} / 1$ & 485 & 359 & 194 & 49 & 58 & 146 & 107 \\
\hline BOD (Biochemical Oxygen Demand) & $\mathrm{mg} / 1$ & 226 & 162 & 87 & 21 & 24 & 61 & 44 \\
\hline T-N (Total Nitrogen) & $\mathrm{mg} / 1$ & 71 & 64 & 59 & 55 & 64 & 78 & 10 \\
\hline T-P (Total Phosphorus) & $\mathrm{mg} / \mathrm{l}$ & 4.856 & 4.515 & 4.305 & 3.780 & 5.014 & 4.279 & 1.139 \\
\hline Fecal Coliform & Colonies/100ml & - & TNTC & - & TNTC & - & TNTC & TNTC \\
\hline
\end{tabular}

\begin{tabular}{|l|c|c|c|c|c|c|c|}
\hline \multicolumn{1}{|c|}{ Parameters } & Unit & N0: 8 & N0: 9 & N0: 11 & N0: 12 & N0: 13 & N0: 14 \\
\hline TSS (Total Suspended Solid) & $\mathrm{mg} / \mathrm{l}$ & 12 & 54 & 5 & 26 & 20 \\
\hline COD (Chemical Oxygen Demand) & $\mathrm{mg} / \mathrm{l}$ & 97 & 97 & 49 & 68 & 97 \\
\hline BOD (Biochemical Oxygen Demand) & $\mathrm{mg} / \mathrm{l}$ & 44 & 41 & 22 & 25 & 47 \\
\hline T-N (Total Nitrogen) & $\mathrm{mg} / \mathrm{l}$ & 8 & 4 & 6 & 7 & 126 \\
\hline T-P (Total Phosphorus) & $\mathrm{mg} / \mathrm{l}$ & 0.740 & 0.436 & 0.961 & 1.011 & 1.281 & 1.433 \\
\hline Fecal Coliform & Colonies/100ml & TNTC & TNTC & TNTC & TNTC & TNTC & TNTC \\
\hline
\end{tabular}

- TNTC - Too Numerous to count.

Remark: N0:1 - Inlet: Thong Khankham (Community)

N0: 2 - Outlet: Thong Khankham (Community)

N0: 3 - Inlet: Khua Luang (School)

N0: 4 - Outlet: Khua Luang (School)

N0: 5 - Inlet: Khua Luang (Temple)

N0: 6 - Outlet: Khua Luang (Temple)

N0: 7 - Ban Savang canal

No: 8 - Hong Kaikeo canal

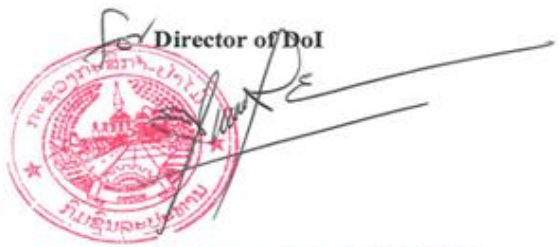

Khammai VONGSATHIEN
N0: 9 - Uay Luay canal

No: 11 - Hong Xaeng canal

No: 12 - Hong Kea canal

N0: 13 - Hong Pasak canal

N0: 14 - Hong Chan canal

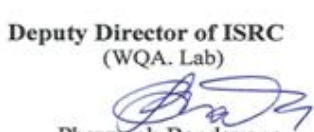

Phayvanh Bandavong 
Laos National standard of Wastewater Discharge in Urban area

\begin{tabular}{|c|c|c|c|c|c|c|}
\hline \multirow{2}{*}{ 16. Presers } & \multirow{2}{*}{ Wail } & \multicolumn{5}{|c|}{ 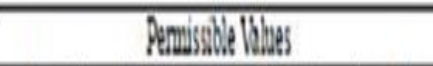 } \\
\hline & & $d$ & $\bar{B}$ & l & $D$ & 8 \\
\hline $1 \mathrm{BOD}$ & \pm घ! & 10 & 30 & 30 & Q & 200 \\
\hline 1 S Susveden Solids & $\pm \mathbb{l}$ & 30 & 4 & 30 & 30 & $\mathbb{N}$ \\
\hline 3 Sertebibie Soids & $\pm \mathbb{t}$ & 05 & 0.5 & 0.5 & 13 & . \\
\hline 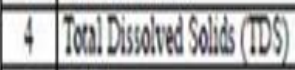 & ㅃ⁈ & 3,00 & .500 & 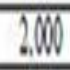 & 150 & . \\
\hline \begin{tabular}{l|l}
3000 \\
\end{tabular} & ㄸ? & 110 & 130 & 100 & 330 & 40 \\
\hline 0 Sulfes & 빠. & 10 & 10 & 30 & 40 & . \\
\hline 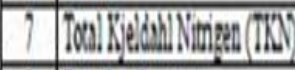 & ㅃ‼ & 3 & 35 & 40 & 4 & . \\
\hline 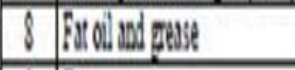 & ㅃ? & D & 10 & II & 10 & 100 \\
\hline 9 Tementiver & " & in & in & 40 & in & in \\
\hline 10 10 &. & 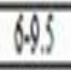 & 8.0 .5 & 6.95 & 6.05 & 0.95 \\
\hline
\end{tabular}

\begin{tabular}{|c|c|c|c|}
\hline 10 & Bulderyng & Cinten & Greans) \\
\hline 1 & 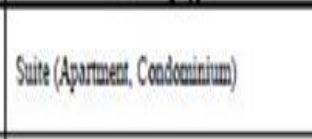 & 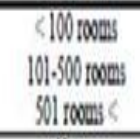 & $\begin{array}{l} \\
C \\
B\end{array}$ \\
\hline 1 & | Houl Grus:Bus: & 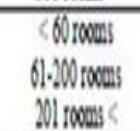 & $\begin{array}{l}D \\
C \\
B\end{array}$ \\
\hline$i$ & Dreivivy & 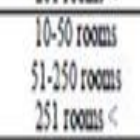 & $\begin{array}{l}1 \\
D \\
B\end{array}$ \\
\hline 4 & Bospind linis & $\begin{array}{l}16 \text { Sentice } \\
1.30 \text { keds } \\
30 \text { beds }\end{array}$ & $\begin{array}{l}C \\
B \\
A\end{array}$ \\
\hline \multicolumn{4}{|c|}{ Builing lisere } \\
\hline 3 & 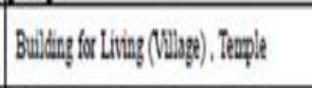 & 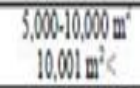 & $\begin{array}{l} \\
\vdots\end{array}$ \\
\hline 6 & 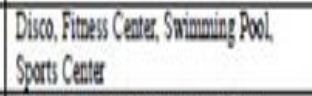 & 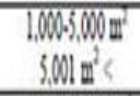 & $\begin{array}{l}B \\
D\end{array}$ \\
\hline$?$ & 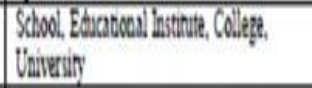 & 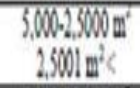 & $\begin{array}{l}B \\
A\end{array}$ \\
\hline 8 & 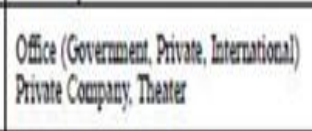 & 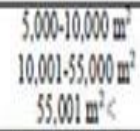 & $\begin{array}{l}C \\
B \\
A\end{array}$ \\
\hline 1 & 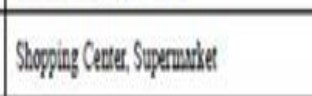 & 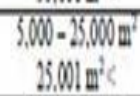 & $\begin{array}{l}B \\
A\end{array}$ \\
\hline 10 & Yastert & 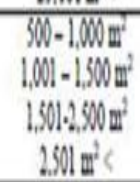 & $\begin{array}{l}1 \\
D \\
C \\
B \\
1\end{array}$ \\
\hline II & Resosum & 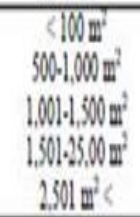 & $\begin{array}{l}1 \\
\vdots \\
0 \\
B \\
1 \\
A\end{array}$ \\
\hline 12 & Semine Cerer (Yoodithe (x) & 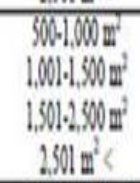 & $\begin{array}{l}D \\
D \\
C \\
B \\
A\end{array}$ \\
\hline 11 & 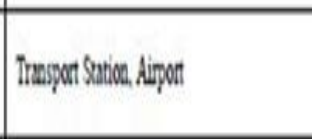 & 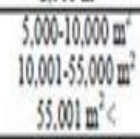 & $\begin{array}{l}1 \\
B \\
A\end{array}$ \\
\hline 14 & 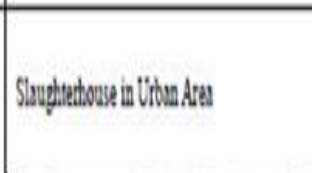 & 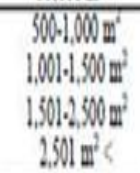 & $\begin{array}{l}D \\
C \\
B \\
1\end{array}$ \\
\hline
\end{tabular}

